\title{
Do outro lado do espelho
}

As imagens da Química são múltiplas, podem ser construidas de dentro ou serem olhares de fora; a forma como somos vistos por criadores de imagem. exteriores à nossa profissão, pode ser um excelente ponto de partida para dis. cutir a Química! Comparar como somos vistos por divulgadores da Ciência de mérito ou por um artista de Banda Desenhada pode permitir um confronto esclarecedor. Propōe-se e comentam-se algumas imagens de clássicos de Banda Desenhada como Fantasio e Spirou de Franquin. Asterix o gaulês de Uderzo e Goscinny, Tintin de Hergé e ainda Blake e Mortimer de Edgar P. Jacobs. Em alternativa ou complemento propōe-se também dois romances policiais, um de Dorothy L. Sayers e outro de Conan Doyle, que têm como protagonistas Lord Peter Wimsey e Sherlock Holmes. O confronto ê feito com dois livros belissimos escritos a partir de dentro: A tabela periódica de Primo Levi e Uma biografia da água de Philip Ball.

Estas figuras falam não só da nossa actual imagem, mas também de como evoluiu ao longo dos anos. 0 druida Panoramix, das aventuras de Astérix e Obélix é o paradigma do alquimista bem sucedido, fig 1; a poção ê mágica, os ingredientes secretos e transmitidos de geração em geração, de druida em druida; mais, de ouvido para ouvido de druida: segredo absoluto e total! 0 Professor Girassol, assim como Mortimer são uma imagem bem mais próxima de nós, terão cinquenta anos de data de criação, mas, ainda assim, o cientista que mostram já não existe. 0 homem do saber universal, que se sente tẫo à vontade nos domínios da Fisica, indo à lua ou construindo o indestrutivel Espadão, como da Quimica ou Medicina, jầ năo nos habita. O conde de Champignac, das aventuras de Spirou e Fantasio, reflecte também essa imagem do Cientista, versátil e brilhante em qualquer área do saber; no entanto, a figura do Conde apresenta a particularidade de ir evoluindo nos seus saberes ao longo das aventuras, ou seja, acompanha o ritmo dos tempos; nas primeiras aventuras (fig 2) é quase o druida alquimista que prepara poções a partir dos seus mágicos cogumelos, nas ültimas já usa as mais modernas técnicas de espectroscopia e mesmo o microscópio electrónico (fig 2) [1]. Por fim temos o Gaston Lagaffe sempre em busca da ideia genial que The permitirá obter uma patente de milhōes; tem um fraquinho pela Quimica e uma perseverança, curiosidade e entusiasmo vitais, vale a pena assistir às suas broncas!

0 livro "O caso dos cogumelos venenosos" editado pela Vampiro [2,3] tem uma intriga fabulosa, em que o criminoso só é descoberto graças à Química: uma Quimica de nivel universitário para a altura. Um gentleman reformado, com uma bonita e muito jovem esposa, tem uma paixão por cogumelos selvagens e outros alimentos que se podem apanhar nos bosques; ervas, bagas e outros que podem dar pratos deliciosos, sendo o custo apenas o de saber procurar. Este gentleman um pouco cinzento em muitos outros aspectos, está a preparar um pequeno e delicioso livro sobre este tema; a maior parte dos seus concidadãos ingleses é muito ignorante sobre este assunto, e como ta absolutamente desconfiados, ninguém acredita que um cogumelo pode ser um manjar dos deuses![4] De tal forma desconfiam, que acreditam que este apaixonado especialista possa ter cofundido um Amanita phalloides com uma espécie comestivel! Acreditem que qualquer apanhador de cogumelos vos dirá que isso é impossível! O crime será descoberto porque, numa reviravolta sensacional da investigação, se descobre que na "sopa venenosa" o principio activo era uma mistura de dois isómeros ópticos; ora, no cogumelo selvagem, como em qualquer ser vivo, existe apenas um dos isómeros! Ou seja, o princípio activo letal era de síntese. Dos muitos contos e aventuras de Sherlock Holmes é fácil escolher; o diletante eclético usa a química como mais uma ferramenta na sua luta contra o crime [3].

O livro de Primo Levi, a Tabela Periódica, è uma dádiva de um químico que ama a sua profișãa. A tradução que temos da Gradiva não é perfeita mas, pelo menos, tem o mérito de existir. 0 conto sobre o zinco será sempre um excelente ponto de partida para a beleza imperfeita da Química; Levi foi também aquele que soube como mostrar que a Tabela Periódica é uma poesia: "Que vencer a matéria é compreendê-la, e compreender a matéria é necessário para compreender o Universo e nós mesmos: e que portanto a Tabela Periodica de Mendeleev, que justamente naquelas semanas aprendiamos laboriosamente a desenredar, era uma poesia ..." [5]

A biografia da água de Philip Ball já foi livro escolhido no "Ex-libris" [6]: aproveitando 0 aniversário da descoberta do oxigénio, vale a pena pegar no capítulo 5 (parte II), onde ciência e aventura se misturam para nos falar de uma das mais importantes descobertas do Homem.

As imagens ai ficam, na página do aluno, para brincar, discutir e percebermos como os outros nos vêem do outro lado do espelho; muitas outras imagens, textos, poesias poderão ser recolhidas e discutidas. Esse será o desafio para os alunos, descobri-las e olhar para elas!

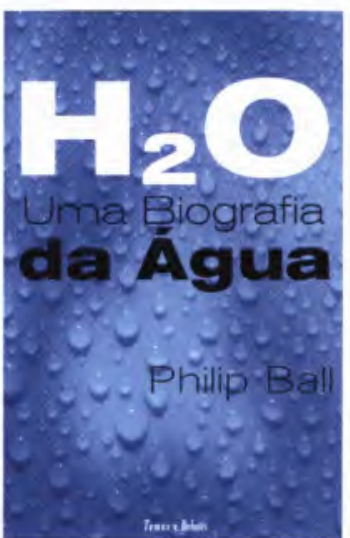

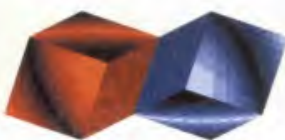

Il sistema periodico

șis

\section{Interesse da Actividade}

Estas imagens/textos foram escolhidas para servir como ponto de partida para uma discussão sobre o que è a Química, o que investiga, o que descobre, a sua utilidade e impacto na sociedade. No entanto, podem, com vantagem, ser utilizadas para introduzir de forma lúdica aspectos vários da Quimica; o astrónomo, o Professor Hipólito Calis de Tintin e a Estrela Misteriosa, pode ser uma bonita imagem para introduzir um espectro de riscas, fig 4, e

até para ajudar a enquadrá-lo na sua realidade histórica, no contexto de uma época; basta olhar para os trajes do Professor e facilmente nos apercebemos que os tempos eram outros. As broncas do Gaston podem ajudar quer a enfatizar o que não se deseja obter de um revestimento polimérico, fig. 5 , quer a partir para uma discussão detalhada sobre as propriedades a que deverá obedecer. As imagens da Banda Desenhada, nomeadamente destes clássicos fabulosos da geração de ouro belga, são belas e expressivas, guardam-se na memória com carinho e partilham-se com divertido prazer.

\section{Referências}

[1] Spirou et les hommes boules, vol 17, Ed Dupuis; as imagens são retiradas de um conto Spirou et les petits formats.

[2] Dorothy L. Sayers, "O caso dos cogumelos venenosos", Publicaçōes EuropaAmérica.

[3] Samuel M. Gerber (ed.), "Chemistry and crime, from Sherlock Holmes to today's courtroom", American Chemical Society, 1983.
4] mas o Amanita caesarea lá está para mostrar que até dos imperadores foram favoritos.

$[5]^{\prime \prime}(\ldots)$ Che vincere la materia è comprenderla, e comprendere la materia è necessario per comprendere l'universo e noi stessi: e che quindi il Sistema Periodico di Mendeleev, che proprio in quelle settimane imparavamo laboriosamente a dipanare, era una poesia, (...)"

[6] J. J. Moura, Quimica - Boletim da Sociedade Portuguesa de Quimica, 88 (2003) 19 

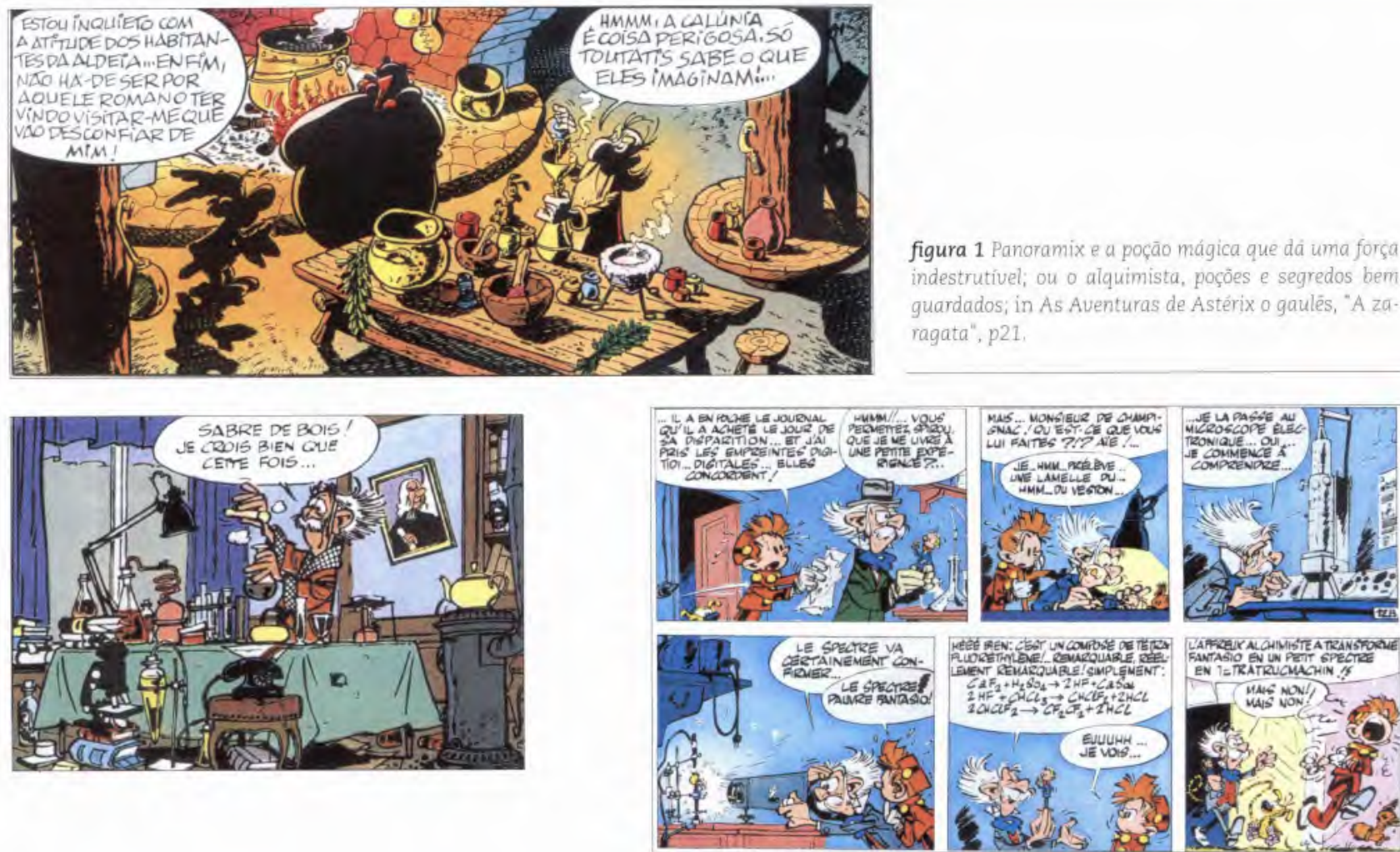

figura 1 Panoramix e a poçâo mágica que dá uma força ndestrutivel; ou o alquimista, poçōes e segredos bem ragata", p21.
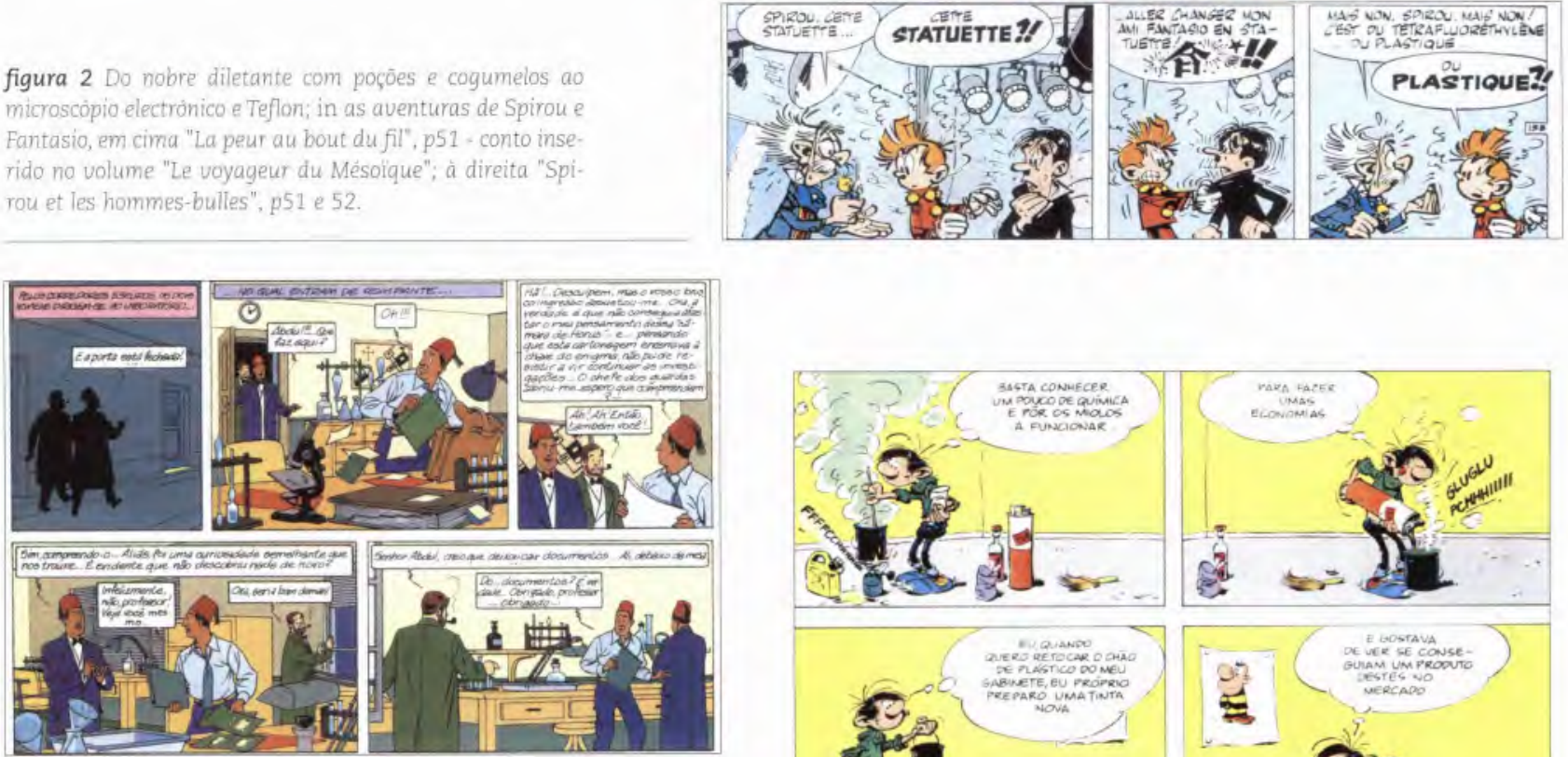

figura 3 A Química no Museu, nos anos 50; provetas e testes microgui.

nica Quântica : in as quenturas de Blake e Mortimer "O mistério da gran
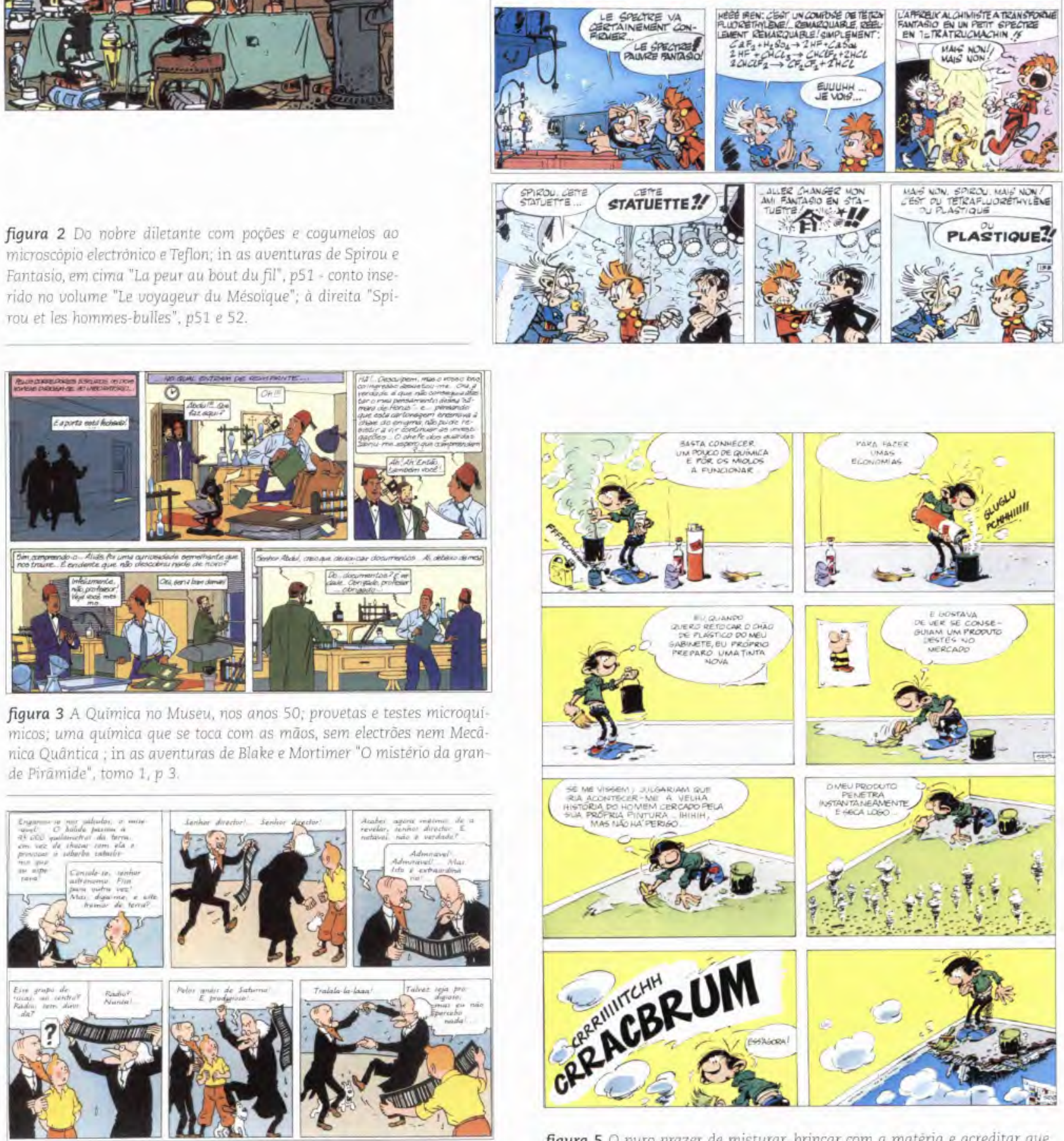

figura 


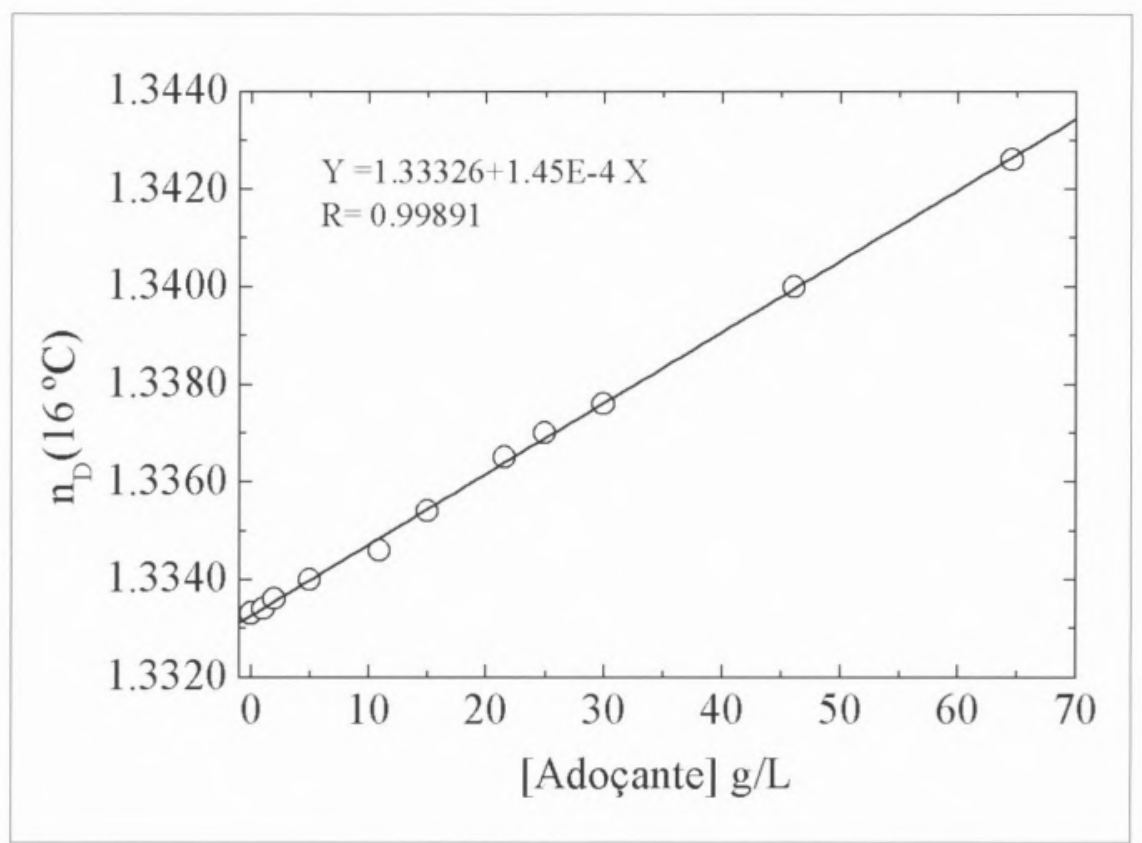

figura 4 Recta de calibração para o Aspartame.

rá escolher, por exemplo, Coca-Cola light, Pepsi light', 7-Up light ${ }^{\circ}$, entre outras.

Determine o teor de aspartame nas bebidas através da curva de calibração. Também nestes casos, podemos ter uma mistura de adoçantes, que vão contribuir para o índice de refracção da bebida, pelo que os resultados obtidos deverão também ser lidos com alguma reserva.

\section{Na aula...}

Uma das curvas de calibração obtida numa aula de laboratório deu origem à seguinte equação:

$$
y=1,3326+1,4480 \times 10^{-4} x
$$

As soluções foram as preparadas de acordo com os dados da tabela 1, ponto 2.1 .

Os mesmos alunos fizeram a determinação do teor de açúcar em diferentes bebidas, com base nesta recta de calibração. Os resultados apresentam-se na Tabela 4.

Na tabela 5 apresentam-se os resultados obtidos, de acordo com o procedimento descrito, agora para um conjunto de bebidas light, ou seja adoçadas com aspartame.

\section{Notas finais}

$\mathrm{O}$ aluno pode verificar que ao beber um litro de um qualquer refrigerante usualmente consumido para matar a sede, ingere uma quantidade geralmente superior a $100 \mathrm{~g}$ de açúcar!! Se ingerir uma garrafa de $330 \mathrm{~mL}$, consome algo como $30 \mathrm{~g}$ de açúcar o que é equivalente a cerca de 5 (ou mais) pacotes de açúcar para café. Ao utilizar adoçante, pelo contrário, ingere-se uma quantidade significativamente menor de composto (cerca de 100 vezes) reduzindo-se, em simultâneo, o conteúdo calórico da bebida.

A técnica de refactometria revela-se de muito simples utilização sem necessitar de grandes recursos, podendo este trabalho constituir um ponto de partida para a exploração de outros temas, em aulas de laboratório.

\section{Agradecimentos}

Aos alunos da disciplina de Laboratórios de Química IV (Licenciatura em Química, Ramo Educacional) que em muito contribuiram para o melhoramento deste trabalho.

\section{Bibliografia}

[1] http://food.oregonstate.edu/sugar/ com6.html
[2] http://food.oregonstate.edu/sugar/ index.html

[3] http://www.metrohm.com/applications/ ic/sugar/sugar_idx.html

[4] S. K. Henderson, C. A. Fenn, J. D. Domijan, "Determination of Sugar Content in Comercial Beverages by Density: A Novel Experiment for General Chemistry Courses", J. Chem. Educ., 1998, 75, 1122

[5] Y. Roggo, L. Duponchel, B. Noe, J. -P. Huevenne, "Sucrose Content Determination of Sugar Beets by Near Infrared reflectance Spectroscopy. Comparison of Calibration Methods and Calibration Transfer", J. Near Infrared Spectrosc., 2002, 10, 137

[6] http://www.sbreb.org/99/Production/ 99p148.htm

[7] J. M. Garrigues, M. Akssira, F. J. Rambla, S. Garrigues, M. de la Guardiã, "Direct ATRFTIR Determination of Sucrose in beet root", Talanta, 2000, 51, 247

[8] E. Hughes, Jr., V. Jelks, 'The Determination of the Concentrations of Sugar Solutions by Laser refractometry", J. Chem. Educ.,

1988, 65, 1007

[9] http://www.lafacu.com/apuntes/fisica/ ABBE_ERNST/default.htm

[10] http://www.geocities.com/ondascenter/ a.html 